\title{
Research on the high activity of REY zeolite in fluid catalytic cracking reaction
}

\author{
Zhaoyong Liu $\cdot$ Zhongdong Zhang $\cdot$ \\ Hongchao Fan • Yi Wang • Pusheng Liu • \\ Chaohe Yang
}

Received: 8 May 2014/ Accepted: 8 July 2014/Published online: 26 August 2014

(c) The Author(s) 2014. This article is published with open access at Springerlink.com

\begin{abstract}
In this paper, a novel REY zeolite, modified with rare earth through short process of preparation technology and rare earth location technology was introduced. Compared with routine REY zeolite, micro-activity test (MAT) conversion of the novel REY increased by $18 \%$ at least. The catalytic cracking performances of the catalysts were tested on a fixed-fluid-bed bench unit. The results showed that when compared with CAT-old, the conversion of CAT-new catalyst increased by $1.60 \%$ and heavy oil yield decreased by $0.23 \%$; the total liquid and light oil yield increased by 1.01 and $0.55 \%$, respectively. Motor octane number and research octane number of gasoline produced by CAT-new sample have increased 0.1 and 1.0 unit, respectively. Therefore, it has good application prospect and remarkable economic benefit.
\end{abstract}

Keywords Y zeolite - Rare earth - MAT conversion . Catalyst · FCC

\section{Introduction}

In recent years, the demand for catalyst with high activity and activity stability has been growing strongly in China. As domestic feedstock of chemical industry was becoming more and more inferior, $\mathrm{Y}$ zeolites, which were the major

\section{Z. Liu $(\bowtie) \cdot$ Z. Zhang $\cdot$ C. Yang}

State Key Laboratory of Heavy Oil Processing, CNPC Key

Laboratory of Catalysis, China University of Petroleum,

Qingdao 266555, China

e-mail: 1zy0539@126.com

Z. Liu $\cdot$ Z. Zhang $\cdot$ H. Fan $\cdot$ Y. Wang $\cdot$ P. Liu Lanzhou Petrochemical Research Center, China National Petroleum Corporation, Lanzhou 730060, China rate-controlling components in most modern hydrocarbon cracking catalysts, should remain extremely stable during cracking [1,2]. Nowadays, almost all zeolitic fluid catalytic cracking (FCC) catalysts are prepared by the ion exchange of rare earth (RE) cations owing to the high activity and proper hydrothermal stability in many reactions.

$\mathrm{RE}$ cations are transferred into zeolite $\mathrm{Y}$ structures following the procedure below [3]. Initially, the RE cations usually exist as RE $\left(\mathrm{H}_{2} \mathrm{O}\right)_{n}^{3+}$ in aqueous solution, and those located in super-cages yield $\mathrm{RE}(\mathrm{OH})^{2+}$ via dehydration during calcination and hydrothermal treatments. The RE $(\mathrm{OH})^{2+}$ cation's diameter is approximately $0.23 \mathrm{~nm}$ and the sodalite cage is sized $0.66 \mathrm{~nm}$, which enables the migration of RE cations from the super-cages to the sodalite cage. However, RE $(\mathrm{OH})^{2+}$ cations and oxygen would react to form $\mathrm{RE}$ oxides that then unexpectedly spread to zeolite surface rather than move into the sodalite cages.

However, as for modification of zeolite Y, the proportion of RE in sodalite cage can not be over 60-70\% [4]. More than $30 \%$ RE cations migrate from sodalite cage to super-cages. As a result, the loss of RE cations reduces cracking activity and changes product distributions. Therefore, how to maintain the retention rate of RE cations in sodalite cage is very important. In this paper, a new method was developed to locate all of RE cations in the sodalite cage by a one-step method.

\section{Experimental section}

Preparation of novel zeolite and catalyst

The NaY zeolites used in this work were obtained from the catalyst plant of Lanzhou Petrochemical Company, 
Fig. 1 Migration of RE cations from the super-cage to the sodalite cage
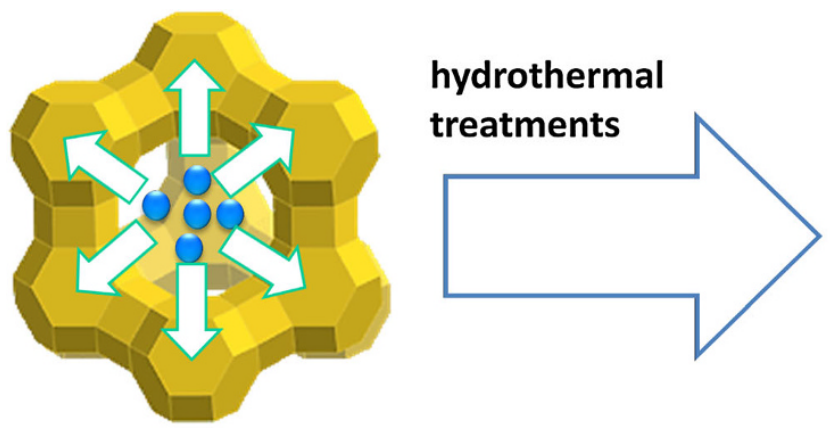

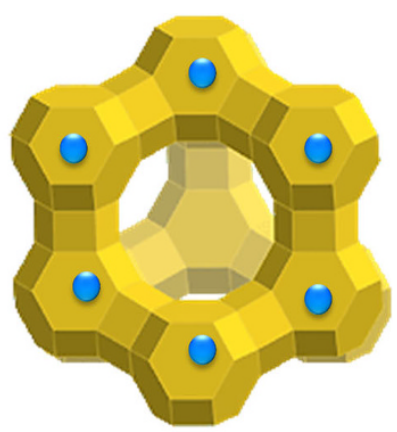

\section{RE cation}

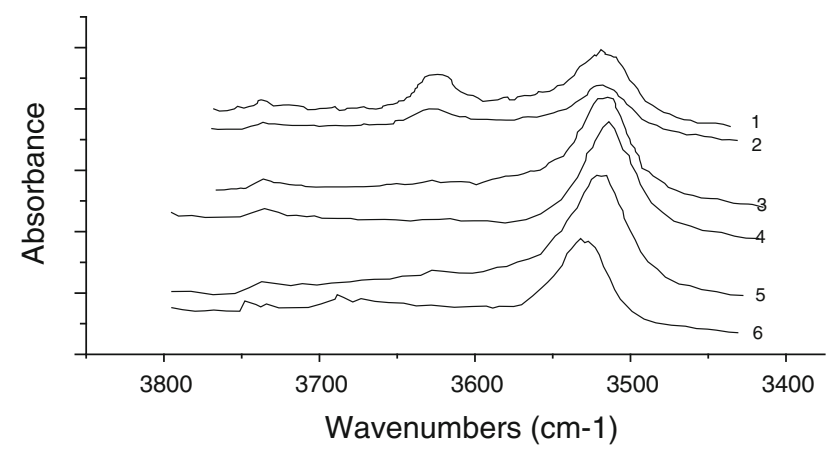

Fig. 2 Infrared analysis curves of RYS in different calcination temperature (RYS- $190{ }^{\circ} \mathrm{C}$, RYS-2 $150{ }^{\circ} \mathrm{C}$, RYS-3 $350{ }^{\circ} \mathrm{C}$, RYS-4 $450{ }^{\circ} \mathrm{C}$, RYS-5, RYS-6 $550{ }^{\circ} \mathrm{C}$ )

PetroChina, China. In a typical process, $\mathrm{NaY}$ was mixed with $\mathrm{La}\left(\mathrm{NO}_{3}\right)_{3}$ (Fig. 1). $6 \mathrm{H}_{2} \mathrm{O}$ solution by ion exchanges, and then reacted at a certain temperature and pressure for $1 \mathrm{~h}$. Then, the mixture was filtered and dried at $100{ }^{\circ} \mathrm{C}$ for $8 \mathrm{~h}$ and calcined at a certain temperature for $2 \mathrm{~h}$ in a $100 \%$ steam environment. NaY was converted to RE-modified $\mathrm{Y}$ zeolite form, which was denoted as RYS. The calcination temperature of RYS and corresponding serial number are shown in Fig. 2. The RE-modified Y zeolite obtained by impregnation at same conditions was named as RYI.

In the catalyst preparation process, one RYS zeolite, a Kaolin matrix (Suzhou Kaolin Company, China), and a silica sol matrix, were mixed together and shaped by spraydrying to obtain a microspheroidal catalyst. This catalyst was named as CAT-new. The old catalyst was prepared by adding RYI to replace RYS zeolite. The old catalyst was marked as CAT-old.

\section{Catalytic cracking tests}

The zeolites were subjected to MAT by ASTM Method D-3907. Prior to MAT test, the samples were hydrothermally deactivated in a laboratory furnace at $800{ }^{\circ} \mathrm{C}$ for
Table 1 Main properties of Xinjiang feedstock

\begin{tabular}{llll}
\hline Items & $\begin{array}{l}\text { Xinjiang } \\
\text { VTB }\end{array}$ & $\begin{array}{l}\text { Xinjiang } \\
\text { VGO }\end{array}$ & $\begin{array}{l}\text { Mixture (VTB/ } \\
\text { VGO }=3 / 7)\end{array}$ \\
\hline $\begin{array}{l}\text { Density }\left(20{ }^{\circ} \mathrm{C}\right), \\
\left(\mathrm{g} \mathrm{cm}^{-3}\right)\end{array}$ & 944.2 & 883.8 & 901.8 \\
$\begin{array}{l}\text { Residue carbon, } \\
\text { wt\% }\end{array}$ & 9.87 & 0.07 & 3.10 \\
Average molecule & 828 & 319 & 390 \\
Simulated distillation $\left({ }^{\circ} \mathrm{C}\right)$ & & \\
IBP & 420 & 286 & 306 \\
$10 \%$ & 435 & 347 & 339 \\
$30 \%$ & 465 & 392 & 372 \\
$50 \%$ & - & 392 & 372 \\
$70 \%$ & - & 453 & 416 \\
$90 \%$ & - & - & 502 \\
\hline
\end{tabular}

certain time in a $100 \%$ steam environment. RYI and RYS were tested on a FFB unit. The tests were carried out under the typical conditions for FCC units: the cracking temperature is $500{ }^{\circ} \mathrm{C}$; catalyst to oil mass ratio is 4.0 ; weight hourly space velocity is $15 \mathrm{~h}^{-1}$. Prior to the FFB test, both CAT-old and CAT-new were steam-deactivated at $800{ }^{\circ} \mathrm{C}$ for $10 \mathrm{~h}$ in a fluid bed in $100 \%$ steam. The chemical composition of the product FCC gasoline was determined by an online GC-MS. The feedstock (as shown in Table 1) was a mixture of $70 \%$ Xinjiang vacuum gas oil (VGO) and $30 \%$ Xinjiang vacuum tower bottom (VTB).

Physicochemical characterization

The element content was analyzed by the X-ray fluorescence spectrum (XRF) method on a Rigaku ZSX primus operated at $50 \mathrm{kV}$ and $40 \mathrm{~mA}$. After the pretreatment, the sample was cooled to $100{ }^{\circ} \mathrm{C}$ and saturated with $\mathrm{NH}_{3}$ gas. Then the $\mathrm{NH}_{3}$-TPD was carried out under a constant flow of $\mathrm{He}(50 \mathrm{ml} \mathrm{min}-1)$ from 100 to $700{ }^{\circ} \mathrm{C}$ at a heating rate 
of $15^{\circ} \mathrm{C} \mathrm{min}{ }^{-1}$. The desorbed ammonia was monitored continuously with a gas chromatograph equipped with a thermal conductivity detector. Attrite index was measured in a home-made attrite machine. Textural properties were determined by $\mathrm{N}_{2}$ adsorption at $77 \mathrm{~K}$ on an ASAP-2010 instrument (Micromeritics, USA). Prior to measurement, the sample was outgassed at $573 \mathrm{~K}$ for $12 \mathrm{~h}$. Micropore volumes and external surface areas were calculated from the t-plot method. FT-IR spectroscopy was performed on a Nexus FT-IR instrument (Nicolet Co, USA) to study the acidity of zeolite. Pretreatment of the sample was made in the cell at $300{ }^{\circ} \mathrm{C}$ under vacuum for $2 \mathrm{~h}$. Then purified pyridine vapor was adsorbed on to the zeolite at room temperature. The excess of pyridine was removed under vacuum over two consecutive $(1 \mathrm{~h})$ periods of heating at 200 and $350{ }^{\circ} \mathrm{C}$, respectively, each of them followed by IR measurements.

\section{Results and discussion}

\section{Calcination conditions}

RE cations were transferred into zeolite $\mathrm{Y}$ following the procedure below [2]. Initially, the RE ions usually existed as $\mathrm{RE}\left(\mathrm{H}_{2} \mathrm{O}\right)_{n}^{3+}$ in aqueous solution, and those located in super-cages yield $\mathrm{RE}(\mathrm{OH})^{2+}$ via dehydration during calcination and hydrothermal treatments. The $\mathrm{RE}(\mathrm{OH})^{2+}$ cation's diagram was approximately $0.23 \mathrm{~nm}$ and the size of sodalite cage was sized $0.66 \mathrm{~nm}$, which allowed the migration of RE cations to transfer from the super-cage to the sodalite cage. However, $\operatorname{RE}(\mathrm{OH})^{2+}$ cations and oxygen would react to form RE oxides that would unexpectedly spread to the zeolite surface rather than move into the sodalite cages.

$$
\begin{aligned}
& \mathrm{RE}\left(\mathrm{H}_{2} \mathrm{O}\right)_{n}^{3+} \rightarrow \mathrm{RE}(\mathrm{OH})^{2+}+\mathrm{H}^{+}+\mathrm{H}_{2} \mathrm{O} \\
& \mathrm{RE}(\mathrm{OH})^{2+}(\text { supercage }) \rightarrow \mathrm{RE}(\mathrm{OH})^{2+}(\text { sodalite cage }) \\
& 2 \mathrm{RE}(\mathrm{OH})^{2+}+\mathrm{O}_{2} \rightarrow \mathrm{RE}_{2} \mathrm{O}_{3}+\mathrm{H}_{2} \mathrm{O}
\end{aligned}
$$

The sodalite cage's size was $0.66 \mathrm{~nm}$ and the size of super-cage was $0.74 \mathrm{~nm}$. The smaller the diameter of pore is, the greater the surface tension $(\gamma)$ and the saturated vapor pressure would be. In the calcination process, hydrothermal treatments could increase the migration of RE cations from the super-cage to the sodalite cage. Therefore, it could increase the cracking activity and change product distributions [5]

$\gamma=\frac{\rho \mathrm{ghr}}{2 \cos \theta}$.

The sample catalysts were analyzed by Infrared analysis. As shown in Fig. 2, upon pyridine adsorption at
Table 2 RE cations retention of RYS and RYI in sodalite cage

\begin{tabular}{lllll}
\hline Zeolite & $\begin{array}{l}\text { The mass of } \\
\text { rare earth, } g\end{array}$ & $\begin{array}{l}\text { Recycling } \\
\text { liquor volume, } \\
\mathrm{L}\end{array}$ & $\begin{array}{l}\mathrm{RE}_{2} \mathrm{O}_{3} \text { in the } \\
\text { liquor, } \mathrm{g} \mathrm{L}^{-1}\end{array}$ & $\begin{array}{l}\mathrm{RE} \text { cations } \\
\text { retention, \% }\end{array}$ \\
\hline RYS & 1,000 & 50 & 0.46 & 97.7 \\
$\mathrm{RYI}$ & 1,000 & 50 & 6.20 & 69.0 \\
\hline
\end{tabular}

Table 3 The physicochemical properties of catalysts

\begin{tabular}{lll}
\hline Catalyst & CAT-old & CAT-new \\
\hline $\mathrm{Na}_{2} \mathrm{O}(\mathrm{wt} \%)$ & 0.18 & 0.12 \\
$\mathrm{RE}_{2} \mathrm{O}_{3}(\mathrm{wt} \%)$ & 5.00 & 5.00 \\
Pore volume $\left(\mathrm{cm}^{3} \mathrm{~g}^{-1}\right)$ & 0.37 & 0.38 \\
$\mathrm{~S}_{\mathrm{BET}}\left(\mathrm{m}^{2} \mathrm{~g}^{-1}\right)$ & 284 & 267 \\
Attrite index $(\%)$ & 2.1 & 2.3 \\
MAT conversion $(\%)$ & 66 & 78 \\
\hline
\end{tabular}

ambient temperature and outgassing at 200 and $350{ }^{\circ} \mathrm{C}$, absorption bands associated with the chemisorbed pyridine were observed at 3,650 and $3,540 \mathrm{~cm}^{-1}$, which corresponded to the $\mathrm{O}_{1} \mathrm{H}$ in supercage and sodalite cage sites, respectively. Below $150{ }^{\circ} \mathrm{C}$, acid peak in $3,640 \mathrm{~cm}^{-1}$ was more obvious. However, above $550{ }^{\circ} \mathrm{C}$, acid peak in $3,640 \mathrm{~cm}^{-1}$ was weak, but acid peak in $3,540 \mathrm{~cm}^{-1}$ was more evident, and also acid peak in $3,685 \mathrm{~cm}^{-1}$ appears, which showed extra-framework aluminum in Y zeolite. In conclusion, we should control calcination temperature in the suitable range.

\section{RE cations retention in sodalite cage}

The RE cations retention of RYS was investigated, as shown in Table 2.

As the data for RYS shown in Table 2, the retention rate of RE cations in sodalite cage reached $97.7 \%$ by a onestep ion exchange. Therefore, it has a good application prospect and remarkable economic benefit to reduce the consumption of RE earth.

Physical chemical properties of catalyst

The physical chemical properties of the prepared catalyst are shown in Table 3. According to the analysis of XRF, the CAT-new and CAT-old catalysts showed the similar content of $\mathrm{Na}_{2} \mathrm{O}$ and $\mathrm{RE}_{2} \mathrm{O}_{3}$. At the same time, the two catalysts held the similar pore volume and surface area based on the measurement of $\mathrm{N}_{2}$ adsorption/desorption method. And attrite index also showed similar data. However, MAT conversion showed obvious difference. The corresponding MAT conversion was 66 and 78 for the 
Table 4 Product distribution of the prepared FCC catalysts

\begin{tabular}{lcc}
\hline Catalyst & CAT-new & CAT-old \\
\hline Product distribution (m\%) & & \\
Dry gas & 2.19 & 2.15 \\
LPG & 15.86 & 16.32 \\
C $_{5}^{+}$gasoline & 52.14 & 50.35 \\
Diesel & 15.89 & 16.67 \\
Heavy oil & 5.51 & 6.27 \\
Coke & 7.81 & 7.58 \\
Total & 99.41 & 99.34 \\
Conversion (m\%) & 78.00 & 76.40 \\
Light oil yield (m\%) & 68.03 & 67.02 \\
Total liquid yield (m\%) & 83.89 & 83.34 \\
MON & 82.6 & 82.5 \\
RON & 93.5 & 92.5 \\
\hline
\end{tabular}

CAT-old and CAT-new, respectively. The difference was mainly due to the high activity of RYS. All of RE cations in sodalite cage were helpful for the increase of MAT conversion.

\section{Catalytic cracking tests}

The product distribution and the nature of the resulting gasoline were shown in Table 4. The data showed that, compared with CAT-old, the conversion of CAT-new catalyst increased by $1.60 \%$; heavy oil yield decreased by $0.23 \%$; the total liquid and light oil yield increased by 1.01 and $0.55 \%$, respectively. The overall reaction performance of CAT-new was obviously superior to CAT-old sample. We all know that if catalyst's Y zeolite content decreases, the ability of heavy oil cracking will decline and the product distribution will deteriorate. The activity of catalyst improved though the active component in the catalyst decreased, which was the full evidence of advantages of the new zeolite.

Compared with CAT-old, the motor octane number $(\mathrm{MON})$ and research octane number (RON) of gasoline produced by CAT-new sample can increase 0.1 and 1.0 unit, respectively. The result was very ideal even though the molecular sieve content reduced, which showed that the synergism effect of both ZSM-5 zeolite and new zeolite fully achieved the desired catalytic properties.

\section{Conclusions}

A novel REY zeolite, modified with rare earth through short process of preparation technology and special rare earth location technology was introduced. Compared with catalyst containing routine REY zeolite, the MAT of the catalyst containing novel REY increased by $18 \%$ at least. The catalytic cracking performances of the catalysts were tested on a FFB unit. The results showed that when compared with CAT-old, the conversion of CAT-new increased by $1.60 \%$; heavy oil yield decreased by $0.23 \%$ and the total liquid and light oil yield increased by 1.01 and $0.55 \%$, respectively. Motor octane number (MON) and research octane number (RON) of gasoline produced by CAT-new sample can increase 0.1 and 1.0 unit, respectively. Therefore, it has a good application prospect and remarkable economic benefit.

Acknowledgments The authors thank the Department of Science and Technology Management of PetroChina for providing financial support.

Open Access This article is distributed under the terms of the Creative Commons Attribution License which permits any use, distribution, and reproduction in any medium, provided the original author(s) and the source are credited.

\section{References}

1. Xu M, Liu X, Madon RJ (2002) J Catal 207:237

2. Cerqueiraa HS, Caeirob G, Costac L, Ramôa Ribeiro F (2008) J Mol Catal A Chem 292:1

3. Hunger M, Engelhardt G, Weitkamp J (1995) Microporous Mater 3:497

4. Du X, Gao X, Zhang H, Li X, Liu P (2013) Catal Commun 35:17

5. Fu X (2006) Phys Chem 5:204 